\title{
The efficacy of physical therapy on the improvement of the motor components of visual attention in children with cerebral palsy: a case series study
}

\author{
Vanesa Abuin-Porras' ${ }^{1}$ Paolo Pedersini ${ }^{2}$, Pedro Berjano ${ }^{3}$, Jorge Hugo Villafañe $e^{2, *}$ \\ ${ }^{1}$ Grupo de Investigación en dolor Musculoesquelético y Control Motor UE. Universidad Europea de Madrid, Madrid, Spain \\ 2IRCCS Fondazione Don Carlo Gnocchi, Milan, Italy \\ ${ }^{3}$ IRCCS Istituto Ortopedico Galeazzi, Milan, Italy
}

This paper has attempted to compare the effects of Bobath's concept with control's session on the improvement of visual attention in children with cerebral palsy. A 10 children sample ( 7 girls and 3 boys) aged 6 to 16 years (median, 12 years) was collected. The group who had received Bobath-based treatment crossed-over to control treatment and the previous control group received Bobath-based treatment for once a week. Measures were assessed at pre- and posttreatment. Outcome measure included the visual attention, we used Conners' Kiddie Continuous Performance Test (K-CPT). Bobath's session targeted to crossed- over participants produced greater improvements in K-CPT(RT) (difference $=33.1, P<0.05$ ) at posttreatment compared to the control's session group, whereas the improvement of K-CPT did not differ between groups. The results of this case series study showed a significant improvement on visual attention through the improvement of motor control functions after the Bobath's session over the control's session.

Keywords: Cerebral Palsy, Bobath's concept, Neurodevelopmental treatment, Visual attention

\section{INTRODUCTION}

The motor disorders of cerebral palsy (CP) are often accompanied by disturbances of sensation, cognition, communication, perception, and/or behavior, and/or by a seizure disorder (Bax et al., 2005). Considering the CP from a clinical point of view we can classify it following two different criteria: considering its highly heterogeneous clinic symptoms and considering the number of affected limbs. One of these with high incidence are visual disorders that appear on some children with CP and have a big impact in many everyday functions.

Regarding visual alterations and CP, Hesse et al. (1998) informed that the prevalence is around $50 \%$, considering the available studies, and 7\%-9\% would be several visual alterations. Sal'kov et al. (2011) informed that visual alterations showed by children participated in their study were, ocular movement and coordination dis- orders, oftalmoparesis, horizontal nistagmus, strabismus, convergence problems and visual acuity deficits. In the future, vision impairment will have an impact on dynamic walking stability (Lim et al., 2017). One treatment approach for movement and posture disorders is the Bobath's concept or neurodevelopment therapy due to central neurological injuries, and it's founded on the principles of neural plasticity, brain damage consequences and abnormal movement and posture patterns.

Many study due to analyze therapy's results by comparing preand postintervention results have a common methodological ground as they used self-reported test. Tsorlakis et al. (2004) used instrumental techniques to determine the therapy effects on hemiparesis patient's gait. They found some significant improvements on several gait parameters after intervention. There are some studies including children that compare Bobath with other therapies like AMIE (acupuncture, massage, injection, and exercise) therapy
${ }^{*}$ Corresponding author: Jorge Hugo Villafañe (iD https://orcid.org/0000-0002-3239-7626 IRCCS Fondazione Don Carlo Gnocchi, Piazzale Morandi, 6, Milan, Italy E-mail: mail@villafane.it

Received: November 9, 2018 / Accepted: January 11, 2019
This is an Open Access article distributed under the terms of the Creative Commons Attribution Non-Commercial License (http://creativecommons.org/licenses/by-nc/4.0/) which permits unrestricted non-commercial use, distribution, and reproduction in any medium, provided the original work is properly cited. 
(He et al., 2007) that did not found statistically significant differences after 60 treatment sessions. About the measure instruments, there are some reports about Conners K-CPT test. Pirila et al. (2011) informed 53\% prevalence of attention deficit hyperactivity disorder (ADHD) potential diagnostic children on their 17 children with CP sample.

In conclusion, Bobath therapy effects on brain damage derivate dysfunctions have been more explored in adult population (Antunes et al., 2017; Puce et al., 2018). However, its effects on children are not sufficiently defined. On the other side, the relation between any intervention based on physical therapy principals and visual and attentional functions remains as an uncover topic.

For that reason, the aim of this study is to explore the benefits of Bobath therapy on children considering visual and attentional functions.

\section{MATERIALS AND METHODS}

\section{Design}

We conducted a case series study (approval number: 060520165416). Informed consent was obtained from all children and procedures were conducted according to the Declaration of Helsinki. Previous authorization was obtained from each of the participating centers, meeting the ethic criteria of each one of them. As the children did not leave the schools facilities neither for the assessment or the intervention, the school board was in all moment the maximum responsible for the adequacy of the study to the local legislation.

\section{Sample}

A sample of 10 children ( 7 girls and 3 boys; aged 6 to 16 years) from special educative needs schools was collected. Previous authorization was obtained from each of the participating centers, meeting the ethic criteria of each one of them. As the children did not leave the schools facilities neither for the assessment or the intervention, the school board was in all moment the maximum responsible for the adequacy of the study to the local legislation.

\section{Inclusion criteria}

- Children from 4 to 16 years old with tetraplegic CP diagnostic.

- Cognitive development age higher than 4 years.

- GMFCS-E \& R score equal or higher than III.

- Informed consent signed by their parents or legal tutors.

\section{Exclusion criteria}

- Have a several visual disorder associated to CP that would not allow the performance of the visual attention test.

\section{Variables and measurement}

The predictor variable is that Bobath's concept treatment (I) vs. nonneurological approach control treatment $(C)$, the dependent variable is visual attention.

Measure used Conners's Attention test for Children KCPT (Abuin-Porras et al., 2018) and The Gross Motor Function Classification System (GMFCS) (Garcìa et al., 2016) for CP. KCPT is a computerized test designed to diagnostic attention disorders in children, provides an estimation index of ADHD diagnostic (it uses a 0\%-100\% risk scale).

We are using this to measure visual attention ability. We are going to used reaction time (Stimulous-Response interval in Kiddies Conners Test) (RT) and Omission error in Kiddies Conners Test $(\mathrm{OM})$ as a measure of visual attention ability. GMFCS It is based on self-initiated movement, with emphasis on sitting, transfers, and mobility. The primary criterion to define a five-level classification system was that the distinctions between levels must be meaningful in daily life. ADHD diagnostic and motor control function skills are mediator variables.

\section{Procedure}

All the children have received both treatments, Bobath and nonneurological approach control treatment. After checking successfully the inclusion and exclusion criteria, we asked for the informed consent to children's parents or legal tutors. The procedure included three sessions, called A, B, C and shown in Fig. 1.

$A$, Initial evaluation, collection of personal data from the children (age, sex, diagnosis, visual conditions). Application of GMFCS to evaluate their motor control condition.

$\mathrm{B}$, Control intervention (C),

- Conners's K-CPT application pre intervention: Results (KCPT-PRE-con-OM and KCPT-PRE-con-RT, ADHD, if necessary)

- Control intervention

- Conner's K-CPT application post intervention (KCPT-POScon-OM and KCPT-POS-con-RT)

C, Bobath intervention (I)

- Conners's K-CPT application pre intervention: Results (KCPT-PRE-exp-OM and KCPT-PRE-exp-RT)

- Bobath intervention

- Conner's K-CPT application post intervention (KCPT-POS- 


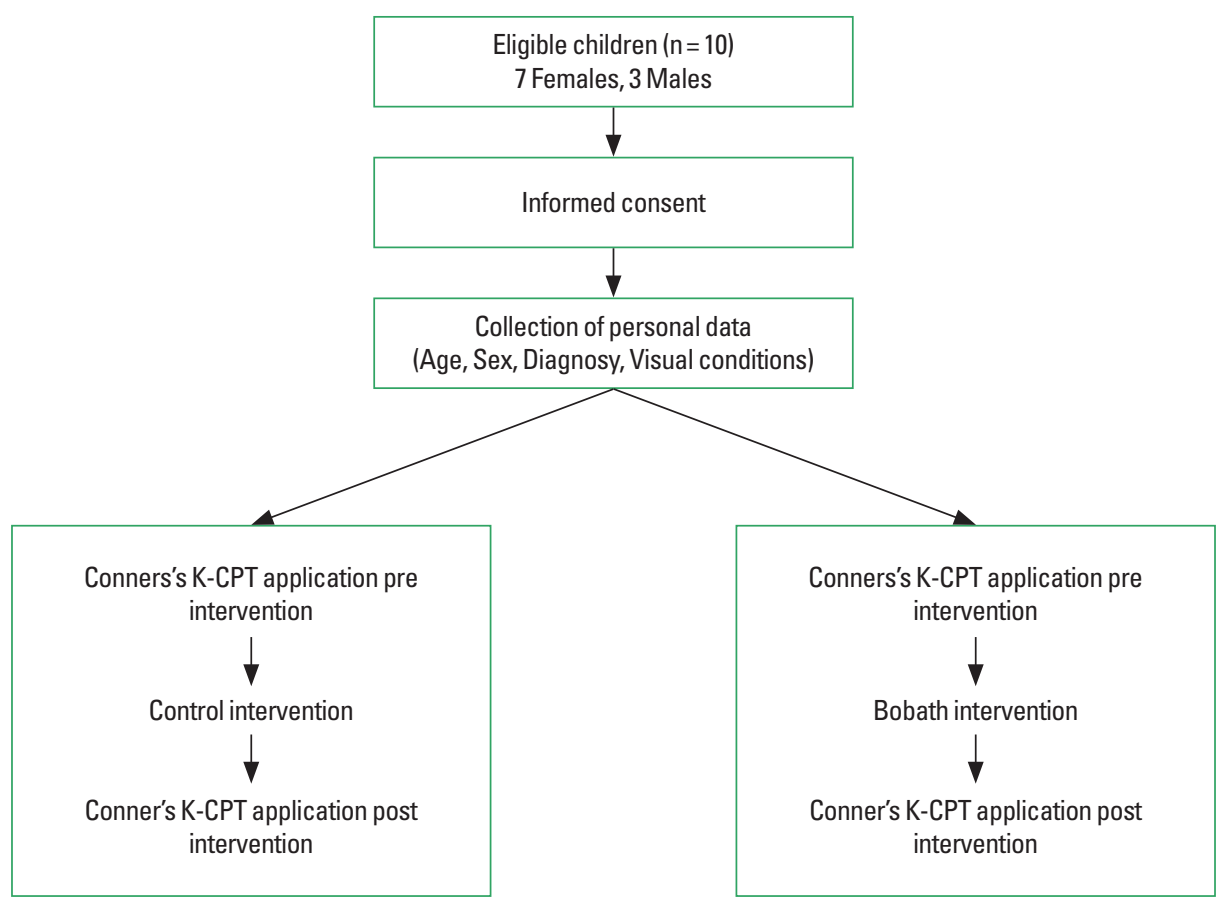

Fig. 1. Conners' Kiddie Continuous Performance Test (K-CPT): Conner's attention test for children.

\section{exp-OM and KCPT-POS-exp-RT)}

We randomly split the sample in two groups, to minimize possible bias due to training on the attention test (as the children would have performed the test once after or before the Bobath intervention). Half of the children's procedure was: Session A - Session B - Session C and the other half procedure was: Session A Session C - Session B. There was a seven day lap between session $\mathrm{B}$ and session $\mathrm{C}$ in both procedures.

The C-Bobath intervention (I) session consisted on $45 \mathrm{~min}$ of treatment following basic principles of the Bobath concept treatment. Described in detail are:

- Reduction of the increased tone. To prepare the pelvic area for sitting position, slow rhythmic movements to reduce the spastic response.

- Training of trunk and head control in sitting position. According to the child's ability to maintain sitting position facilitation by the therapist was provided. The control was performed according to Bobath's concept treatment, and was variable depending on each child and was reduced during the progression of the session as the patients were able to perform better.

- Assisted weight-shifting from one hip to another while seating. Patients should join with their heads the movement of the trunk.
- Assisted rotation of the trunk. Patients should join with their heads the movement of the trunk.

- Voluntary reach with upper limbs. If possible patients should maintain head and trunk stable during the perturbation due to self-initiated movement.

The control treatment consisted on stretching of the upper and lower limbs in a supine position.

\section{Statistics}

Data were analyzed using IBM SPSS Statistics ver. 21.0 (IBM Co., Armonk, NY, USA), conducted following an intention-totreat analysis using the last value forward method. Normal distribution of the sample was analyzed by using the KolmogorovSmirnov test. A one-way analysis of variance with repeated measurements and Bonferroni was used as post hoc test to evaluate statistical significance. For all the data of the study, $P$-values lower than 0.05 were considered significant.

\section{RESULTS}

In the present case series, no subjects dropped out during the different phases of the study, and no adverse effects were detected after the application of the treatments. None of the subjects began drug therapy during the course of the study. 
Table 1. Visual attention results compare OM and RT from K-CPT results between pre- and posttreatment measures

\begin{tabular}{|c|c|c|c|c|c|c|}
\hline \multirow{3}{*}{ K-СРT result } & \multicolumn{4}{|c|}{ Group } & \multirow{2}{*}{\multicolumn{2}{|c|}{$\begin{array}{c}\text { Difference within groups } \\
\text { Post-Pre }\end{array}$}} \\
\hline & \multicolumn{2}{|c|}{ Pre } & \multicolumn{2}{|c|}{ Post } & & \\
\hline & $\operatorname{Exp}(n=5)$ & Con $(n=5)$ & $\operatorname{Exp}(n=5)$ & Con $(n=5)$ & $\operatorname{Exp}(n=5)$ & $\operatorname{Con}(n=5)$ \\
\hline $\mathrm{OM}$ & $19.8(17.7)$ & $24.3(23.4)$ & $27.5(31.8)$ & $28.1(28.3)$ & $7.7^{*}(15.9)$ & $3.8(5.5)$ \\
\hline RT & 640.7 (143.9) & 682.2 (172.5) & 673.8 (186.1) & $676.0(213)$ & $33.1^{*}(96.9)$ & $-5.7(131.6)$ \\
\hline
\end{tabular}

K-CPT, Conners' Kiddie Continuous Performance Test; OM, Omission error in Kiddies Conners Test; RT, reaction time (Stimulous-Response interval in Kiddies Conners Test); Exp, experimental; Con, control.

*Significantly different within groups, $P<0.05$.

Table 2. ADHD intergroup effects on visual motor control therapy effects

\begin{tabular}{|c|c|c|c|c|c|c|}
\hline \multirow{3}{*}{ Variable } & \multicolumn{4}{|c|}{ Group } & \multirow{2}{*}{\multicolumn{2}{|c|}{$\begin{array}{c}\text { Difference within groups } \\
\text { Post - Pre }\end{array}$}} \\
\hline & \multicolumn{2}{|c|}{ Pre } & \multicolumn{2}{|c|}{ Post } & & \\
\hline & $\mathrm{ADHD}(\mathrm{n}=5)$ & Non-ADHD (n=5) & $\operatorname{ADHD}(n=5)$ & Non-ADHD (n=5) & $\mathrm{ADHD}(\mathrm{n}=5+5)$ & Non-ADHD $(n=5+5)$ \\
\hline Con group left & 117.1 (67.9) & $35.1(40.6)$ & $115.7(67.7)$ & $39.1(59.1)$ & $1.4(1.7)$ & $-4.0(19.1)$ \\
\hline Con group right & $121.9(68.4)$ & $51.8(38.6)$ & $117.6(67.4)$ & $36.4(38.5)$ & $4.3(6.0)$ & $15.5(22.7)$ \\
\hline Exp group left & $148.8(39.7)$ & $90.9(63.0)$ & $111.8(56.7)$ & 23.7 (21.4) & $37.0^{*}(18.2)$ & $67.2^{*}(50.9)$ \\
\hline Exp group right & $143.7(43.4)$ & $108.2(57.0)$ & $108.2(57.7)$ & $28.5(30.7)$ & $35.5^{*}(34.7)$ & $49.1^{*}(54.9)$ \\
\hline
\end{tabular}

ADHD, attention deficit hyperactivity disorder (Stimated risk of ADHD in Kiddies Conners Test); Exp, experimental; Con, control.

*Significantly different within groups, $P<0.05$.

\section{Response to treatment}

Outcomes for K-CPT (OM) and K-CPT (RT) demonstrated a significant time factor $(P<0.001)$. The RT and $\mathrm{OM}$ increased for all participants after the treatment period. The post boc analysis revealed significant differences between the twice sessions for the experimental group $(P<0.05)$ (Table 1$)$.

In order to test $A D H D$ effects we have divided the sample into two groups, ADHD (1) and non-ADHD (0), the grouping criterion was the ADHD diagnostics score from K-CPT. We had 5 children who had a score higher than $90 \%$ chance of having ADHD and five children who had a score far lower than that. So we analyzed the Bobath concept treatment vs. Control treatment comparison considering the ADHD diagnostic influence. The IRISCOM-exp left and right decreased for all participants after the treatment period. The post hoc analysis revealed significant differences between the two sessions for the ADHD group $(P<0.05)$ and for the not-ADHD group $(P<0.05)$ (Table 2).

\section{DISCUSSION}

In order to test the Bobath's concept treatments results over visual attention, we have compared OM and RT from K-CPT results between pre- and posttreatment measures. The results do show statistical significant difference in both variables.
Specific Bobath therapy in children with CP improves motor control. Our results match those found by Langhammer and Stanghelle (2003) and Platz et al. (2005) as they found statistically significant effects that supported Bobath therapy as an effective therapy procedure. More precisely, Langhammer and Stanghelle (2003) found a posture control improvement and that was related to weight symmetric distribution and balance control. Those functions are related to visual motor system. Additionally, Platz et al. (2005) showed some positive changes related to muscle tone, that will be in our sample one of the keys to obtain head control and increase visual attention ability. A more adequate muscular tone will facilitate the movements of the eyes concerning to head control against gravity.

Tsorlakis et al. (2004) and Knox and Evans (2002) found in their studies in children improvements in motor function after applying Bobath therapy, using as a measure the Gross Motor Function tests. There is a relationship with their results and ours, from the point of view of the anatomical connection between head and eyes explained by Ferrani. The improvement of the head control implies the betterment of visual attention through the improvements on the visual motor control. The ability to visual attention is important for many reasons, to various combinations with physical and speech disorders, which requires a differentiated approach and that as we have seen, those who have visual disor- 
ders get less improvement of motor skills than those who have not. This makes us understand how much these children need a careful evaluation of visual disorders and then a special education, considering the need for a facilitatory context for learning.

From the ADHD perspective Silva et al. (2014) conclude, as well as we do, that there is a high ADHD prevalence, measured by K- CPT Conners' test, on children with CP. Additionally, they said that children with $\mathrm{CP}$ and tetraplegia are more prone to have attentional problems, since they have both brain hemispheres harmed.

This considerations support the Bobath's concept therapy as a valid instrument to improve visual motor control and therefore visual attention functions in children with $\mathrm{CP}$, all this with a focus on the tiredness of the child. Considering also that improvement of the head control implies the betterment of visual attention through the improvements on the visual motor control.

Our findings confirm benefits that Specific Bobath therapy could have in children with $\mathrm{CP}$, as we see, to improve visual motor control and therefore visual attention functions in children with $\mathrm{CP}$, all this with a focus on the tiredness of the child. Further studies with largest samples should be carried to confirm this affirmation.

In our study we recognize that the sample size was small, although sufficient to determine significance and the lack of a control group. In our study we included all types of visual disorder, could result in different motor performance. It is important that future studies notice which type of visual disorder each included child has. It would necessary a more extensive intervention over time and sessions to test the permanency of the hypothetical changes.

\section{CONFLICT OF INTEREST}

No potential conflict of interest relevant to this article was reported.

\section{ACKNOWLEDGMENTS}

The authors would like to acknowledge all the children participating in this study, their families and the participant schools. The authors would like to thank Barbara Piovanelli for his input and contributions to this study.

\section{REFERENCES}

Abuin-Porras V, Villafañe JH, Jiménez-Antona C, Palacios A, MartínezPascual B, Rodríguez-Costa I. Relationship between attention and bal- ance: a dual-task condition study in children. J Exerc Rehabil 2018;14: 349-355.

Antunes D, Rossato M, Kons RL, Sakugawa RL, Fischer G. Neuromuscular features in sprinters with cerebral palsy: case studies based on paralympic classification. J Exerc Rehabil 2017;13:716-721.

Bax M, Goldstein M, Rosenbaum P, Leviton A, Paneth N, Dan B, Jacobsson B, Damiano D; Executive Committee for the Definition of Cerebral Palsy. Proposed definition and classification of cerebral palsy, April 2005. Dev Med Child Neurol 2005;47:571-576.

García CC, Alcocer-Gamboa A, Ruiz MP, Caballero IM, Faigenbaum AD, Esteve-Lanao J, Saiz BM, Lorenzo TM, Lara SL. Metabolic, cardiorespiratory, and neuromuscular fitness performance in children with cerebral palsy: a comparison with healthy youth. J Exerc Rehabil 2016; 12:124-131.

He J, Dong XL, Duan YH, Zhou HL, Huang CQ, Liu Y, Zhao Y, Chen MJ. Randomized controlled study on AMIE methods for treatment of movement disorder in the child of convulsive cerebral palsy. Zhongguo Zhen Jiu 2007;27:797-800.

Hesse S, Jahnke MT, Schaffrin A, Lucke D, Reiter F, Konrad M. Immediate effects of therapeutic facilitation on the gait of hemiparetic patients as compared with walking with and without a cane. Electroencephalogr Clin Neurophysiol 1998;109:515-522.

Knox V, Evans AL. Evaluation of the functional effects of a course of Bobath therapy in children with cerebral palsy: a preliminary study. Dev Med Child Neurol 2002;44:447-460.

Langhammer B, Stanghelle JK. Bobath or motor relearning programme? A follow-up one and four years post stroke. Clin Rehabil 2003;17:731734.

Lim J, Chang SH, Lee J, Kim K. Effects of smartphone texting on the visual perception and dynamic walking stability. J Exerc Rehabil 2017;13: 48-54.

Pirila S, van der Meere JJ, Rantanen K, Jokiluoma M, Eriksson K. Executive functions in youth with spastic cerebral palsy. J Child Neurol 2011; 26:817-821

Platz T, Eickhof C, van Kaick S, Engel U, Pinkowski C, Kalok S, Pause M. Impairment-oriented training or Bobath therapy for severe arm paresis after stroke: a single-blind, multicentre randomized controlled trial. Clin Rehabil 2005;19:714-724.

Puce L, Marinelli L, Pierantozzi E, Mori L, Pallecchi I, Bonifazi M, Bove M, Franchini E, Trompetto C. Training methods and analysis of races of a top level Paralympic swimming athlete. J Exerc Rehabil 2018;14:612620.

Sal'kov VN, Levchenkova VD, Lobanova LV, Grishina TG, Sheřnkman OG. Visual disorders in children cerebral palsy. Zh Nevrol Psikhiatr Im S S Korsakova 2011;111:8-11. 
Silva D, Colvin L, Hagemann E, Stanley F, Bower C. Children diagnosed with attention deficit disorder and their hospitalisations: population data linkage study. Eur Child Adolesc Psychiatry 2014;23:1043-1050.
Tsorlakis N, Evaggelinou C, Grouios G, Tsorbatzoudis C. Effect of intensive neurodevelopmental treatment in gross motor function of children with cerebral palsy. Dev Med Child Neurol 2004;46:740-745. 